\title{
Quality of Care in Humanitarian Surgery
}

\author{
Kathryn M. Chu $\cdot$ Miguel Trelles $\cdot$ Nathan P. Ford
}

Published online: 13 April 2011

(c) The Author(s) 2011. This article is published with open access at Springerlink.com

\begin{abstract}
Humanitarian surgical programs are set up de novo, within days or hours in emergency or disaster settings. In such circumstances, insuring quality of care is extremely challenging. Basic structural inputs such as a safe structure, electricity, clean water, a blood bank, sterilization equipment, a post-anesthesia recovery unit, appropriate medications should be established. Currently, no specific credentials are needed for surgeons to operate in a humanitarian setting; the training of more humanitarian surgeons is desperately needed. Standard perioperative protocols for the humanitarian setting after common procedures such as Cesarean section, burn care, open fractures, and amputations and antibiotic prophylaxis, and postoperative pain management must be developed. Outcome data, especially long-term outcomes, are difficult to collect as patients often do not return for follow-up and may be difficult to trace; standard databases for post-operative infections and mortality rates should be established. Checklists have recently received significant attention as an instrument to support the improvement of surgical quality; knowing which items are most applicable to humanitarian settings remains unknown. In conclusion, the quality of surgical services in humanitarian settings must be
\end{abstract}

K. M. Chu $(\bowtie) \cdot$ N. P. Ford

Medical Department, Médecins Sans Frontières-South Africa, 49 Jorrisen St, Braamfontein 2017, Johannesburg, South Africa e-mail: kathryn.chu@joburg.msf.org

K. M. Chu

Department of Surgery, Johns Hopkins University, Baltimore,

MD, USA

M. Trelles

Médecins Sans Frontières-Belgium, Surgery, Anesthesia,

Gynecology, and Emergency Medicine Unit, Medical

Department, Rue Dupré 94, 1090 Brussels, Belgium regulated. Many other core medical activities of humanitarian organizations such as therapeutic feeding, mass vaccination, and the treatment of infectious diseases, such as tuberculosis and human immunodeficiency virus, are subject to rigorous reporting of quality indicators. There is no reason why surgery should be exempted from quality oversight. The surgical humanitarian community should pull together before the next disaster strikes.

\section{Introduction}

After three successive hurricanes tore through Haiti in 2008, surgical care was destroyed in the Arbonite region, and an operating theater and hospital had to be set up in a warehouse. In January 2010, a massive earthquake struck in Port-au-Prince, injuring as estimated quarter of a million victims. In the absence of functional surgical services, emergency surgical care was provided in temporary structures, including inflatable hospitals and partially destroyed hospitals.

Such settings are typical for the provision of humanitarian surgical assistance in emergency or disaster settings. Programs are set up de novo within days or hours, and the high number of injuries can overwhelm services. Even after the initial disaster is over, surgical delivery is hindered by the limited number of trained staff members available, limited resources, and poor supply chains.

In such circumstances, ensuring the quality of humanitarian surgical delivery is challenging. Often the quality of the response is unknown, as humanitarian agencies are rarely required to report medical data. Where data are collected, it is usually limited to descriptions of interventions: patient demographics, operative indications, surgical procedures. 
Measures of surgical quality have been categorized into structural, process, and outcome measures [1]. In this article, we briefly review the applicability of these measures to humanitarian settings.

\section{Structural approaches}

Structural approaches to quality measurement relate to the availability and use of certain essential material or human resources. Médecins Sans Frontières (MSF) has established minimum criteria for structural inputs that must be in place before humanitarian surgery can be delivered. They include a safe structure, electricity, clean water, a blood bank, sterilization equipment, a postanesthesia recovery unit, anesthetics, analgesics, antibiotics, and qualified surgery and anesthesia providers [2]. Such indicators could serve as a basis for structural measures of surgical quality in humanitarian settings.

Currently, no specific credentials are needed for surgeons to operate in a humanitarian setting. Most major disasters take place in countries with few trained surgeons. Many agencies recruit surgeons from Europe and North America, but the broad range of general surgery, orthopedic, and gynecology skills needed is often beyond the scope of their training. [3]. MSF and the International Committee for the Red Cross provide additional trauma training for their surgeons. Studies in high-income countries have shown that surgical quality is directly related to surgeon experience [4-7]. Needless to say, the training of more humanitarian surgeons is desperately needed.

\section{Process variables}

Process variables reflect the care provided, such as treatment protocols or specific operative techniques [1]. In the humanitarian setting, standard perioperative protocols for common procedures such as Cesarean section, burn care, open fractures, and amputations are needed. Also needed are protocols for antibiotic prophylaxis and postoperative pain management. Given the high staff turnover and changing acuity of the disaster, such protocols would help ensure the quality of care.

\section{Outcome measures}

Outcome data, especially long-term outcomes, are difficult to collect as patients often do not return for follow-up and may be difficult to trace. This is in stark contrast to what occurs in high-income countries such as the United States, where hospitals and office-based practices providing surgical care must meet Joint Commission criteria to become accredited [8]. Moreover, surgical programs in these more sophisticated settings routinely report outcome data to standard quality improvement programs such as the U.S. National Surgery Quality Improvement Program [9].

Humanitarian surgical programs do not have standardized databases. Interpretation and comparison of data collected by various agencies is difficult. MSF, using a standardized database containing nearly 20,000 procedures, reported an operative mortality rate of $0.2 \%$ [10]. How this compares to other agencies is not known as there are no other reports in the literature to date. For example, numerous agencies performed thousands of procedures during the 2010 earthquake, but mortality and infection rates were not reported [11-15].

\section{Existing tools}

Recent emphasis has been given to improving the quality of surgical care in low-income countries [16]. In 2007, the World Health Organization (WHO) launched the Safe Surgery Saves Lives Project aimed at "improving the safety of surgical care around the world by ensuring adherence to proven standards of care in all states." The WHO Situation Analysis to Assess Emergency and Essential Surgical Care tool [17] has been used to evaluate surgical care in Sierra Leone, Afghanistan, Liberia, Sri Lanka, Tanzania, Mongolia, San Tome and Principe, the Gambia [18], and Ghana [19]. For humanitarian surgery, this tool would be useful as part of a rapid needs assessment but would not alone be sufficient to measure quality.

Checklists have recently received significant attention as instruments to support the improvement of surgical quality [20, 21]. A WHO study demonstrated that implementation of a 19-item operating room checklist demonstrated significant reductions in morbidity and mortality in eight countries with varying resources [21]. Subsequently, implementation of an exhaustive 110-item checklist encompassing all areas of surgical care-including preoperative imaging studies, surgical equipment list, and postoperative care-showed similar results [20]. How these checklists lead to improved outcomes is unclear [22]. Decreases in operative blood loss, for example, would unlikely be the direct result of team members introducing themselves. One theory is that the checklists give the surgeon more "peace of mind" regarding the system, allowing him or her to focus on the operation itself. Critics have cautioned that the checklist cannot be a "stand-alone" solution for quality assurance [23], but it can serve to "reinforce accepted safety practices and foster better communication and teamwork between clinical disciplines" [24]. Humanitarian surgery could benefit from 
Table 1 Elements of humanitarian surgery safety checklist

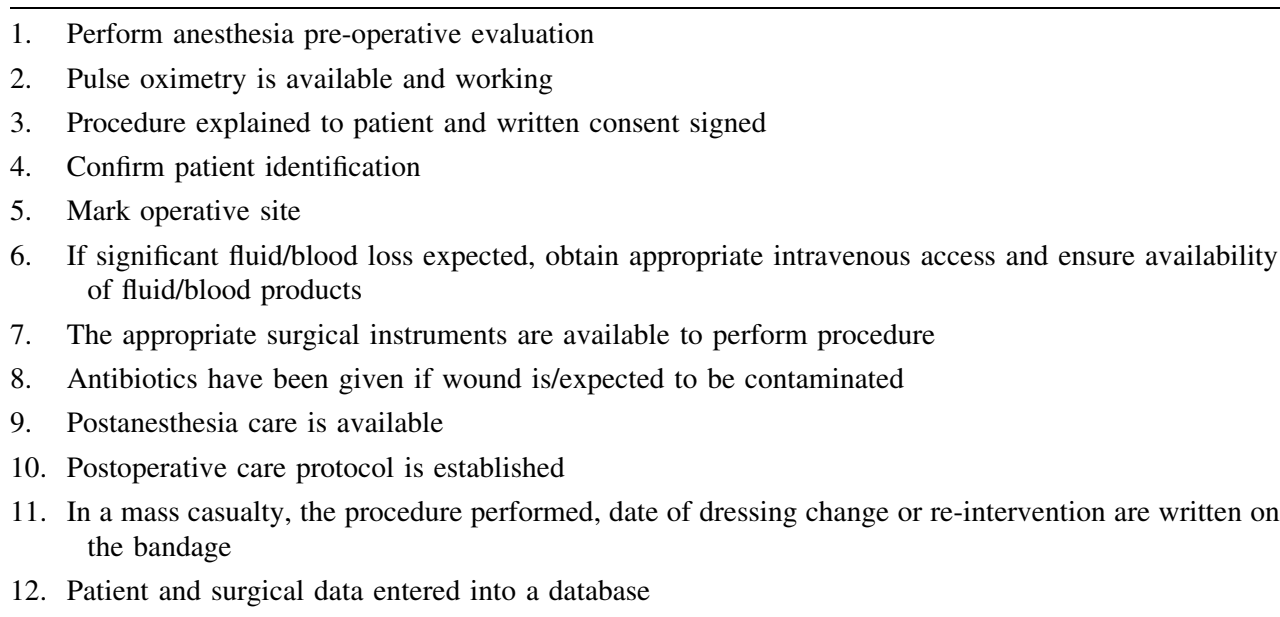

checklists. Staff turnover is high, and often new surgeons arrive every few weeks. Language barriers exist between the local and international staff. It is difficult to enforce protocols with high staff turnover and an overworked staff.

Knowing which items on current checklists are most applicable to humanitarian settings remains unknown. We propose a simple, practical checklist to be adapted for the humanitarian surgery setting (Table 1).

\section{Conclusions}

The quality of surgical services in humanitarian settings is rarely assessed. During emergencies, most countries are grateful for surgical care and do not have the resources to provide oversight. As an increasing number of actors are becoming involved in the delivery of humanitarian surgery, the need to establish a framework for quality surgical delivery is more pressing. The quality of surgical care may be regulated through a combination of structural, process, and output measures that could include minimum standards for safe surgery, the deployment of appropriately trained surgeons and anesthesiologists for these contexts, protocols for pre-operative evaluation, intraoperative management and postoperative care, and standardized databases to record postoperative infection and mortality rates. A simple checklist for each patient can be utilized to ensure compliance. Standardizing data collection can help to evaluate surgical delivery.

There may be resistance to such measures in that they may be considered too cumbersome to implement during emergencies or not relevant for surgeons whose focus is the number of procedures performed. How successful is an operation, though, if the patient dies because of inadequate postanesthesia monitoring? Many other core medical activities of humanitarian organizations-e.g., therapeutic feeding, mass vaccination, treatment of infectious diseases such as tuberculosis and human immunodeficiency virus infection-are subject to rigorous reporting of quality indicators. There is no reason why surgery should be exempted from quality oversight. The surgical humanitarian community should pull together before the next disaster strikes.

Conflicts of interest The authors declare no conflicts of interest.

Open Access This article is distributed under the terms of the Creative Commons Attribution Noncommercial License which permits any noncommercial use, distribution, and reproduction in any medium, provided the original author(s) and source are credited.

\section{References}

1. Birkmeyer JD, Dimick JB, Birkmeyer NJ (2004) Measuring the quality of surgical care: structure, process, or outcomes? J Am Coll Surg 198:626-632

2. McQueen KA, Parmar P, Kene M et al (2009) Burden of surgical disease: strategies to manage an existing public health emergency. Prehosp Disaster Med 24(Suppl 2):s228-s231

3. Chu K (2009) General surgeons: a dying breed? Arch Surg 144:498-499

4. Bilimoria KY, Phillips JD, Rock CE et al (2009) Effect of surgeon training, specialization, and experience on outcomes for cancer surgery: a systematic review of the literature. Ann Surg Oncol 16:1799-1808

5. Dimick JB, Birkmeyer JD, Upchurch GR Jr (2005) Measuring surgical quality: what's the role of provider volume? World $\mathrm{J}$ Surg 29:1217-1221

6. Rogo-Gupta LJ, Lewin SN, Kim JH et al (2010) The effect of surgeon volume on outcomes and resource use for vaginal hysterectomy. Obstet Gynecol 116:1341-1347

7. Wilt TJ, Shamliyan TA, Taylor BC et al (2008) Association between hospital and surgeon radical prostatectomy volume and patient outcomes: a systematic review. J Urol 180:820-828 discussion $828-829$

8. The Joint Commission (2010, Nov 23) Available from: http:// www.jointcommission.org/

9. Ingraham AM, Richards KE, Hall BL et al (2010) Quality improvement in surgery: the American College of Surgeons 
National Surgical Quality Improvement Program approach. Adv Surg 44:251-267

10. Chu KM, Ford N, Trelles M (2010) Operative mortality in resource-limited settings: the experience of Medecins Sans Frontieres in 13 countries. Arch Surg 145:721-725

11. Ginzburg E, O'Neill WW, Goldschmidt-Clermont PJ et al (2010) Rapid medical relief: project Medishare and the Haitian earthquake. N Engl J Med 362:e31

12. MacIntyre NR, Jeffcoat DM, Chan DB et al (2010) The experiences of a surgical response team in Haiti. Am J Orthop (Belle Mead NJ) 39:172-201

13. Merin O, Ash N, Levy G et al (2010) The Israeli field hospital in Haiti: ethical dilemmas in early disaster response. N Engl J Med 362:e38

14. Peranteau WH, Havens JM, Harrington S et al (2010) Re-establishing surgical care at Port-au-Prince General Hospital, Haiti. J Am Coll Surg 211:126-130

15. Sullivan SR, Taylor HO, Pauyo T et al (2010) Surgeons' dispatch from Cange, Haiti. N Engl J Med 362:e19

16. Bickler SW, Spiegel D (2010) Improving surgical care in lowand middle-income countries: a pivotal role for the World Health Organization. World J Surg 34:386-390

17. WHO (2011, Jan 10) Tool for situational analysis to assess emergency and essential surgical care. Available from:
http://www.who.int/surgery/publications/QuickSitAnalysisEESC survey.pdf

18. Kushner AL, Cherian MN, Noel L et al (2010) Addressing the Millennium Development Goals from a surgical perspective: essential surgery and anesthesia in 8 low- and middle-income countries. Arch Surg 145:154-159

19. Choo S, Perry H, Hesse AA et al (2010) Assessment of capacity for surgery, obstetrics and anaesthesia in 17 Ghanaian hospitals using a WHO assessment tool. Trop Med Int Health Jul 14 [Epub ahead of print]

20. De Vries EN, Prins HA, Crolla RM et al (2010) Effect of a comprehensive surgical safety system on patient outcomes. N Engl J Med 363:1928-1937

21. Haynes AB, Weiser TG, Berry WR et al (2009) A surgical safety checklist to reduce morbidity and mortality in a global population. N Engl J Med 360:491-499

22. Birkmeyer JD (2010) Strategies for improving surgical quality: checklists and beyond. N Engl J Med 363:1963-1965

23. Birkmeyer JD, Miller DC (2009) Surgery: can checklists improve surgical outcomes? Nat Rev Urol 6:245-246

24. Sana EM (2010) Implementation of the WHO safe surgery checklist in Tunisia: followed steps and learned lessons. In: International forum on quality and safety in healthcare. WHO, Nice, France 